Western University

Scholarship@Western

Human Environments Analysis Lab (HEAL)

2019

If You Make it Free, Will They Come? Using a Physical Activity Accessibility Model to Understand the Use of a Free Children's Recreation Pass

Andrew F. Clark

Johanna Campbell

Patricia Tucker

Piotr Wilk

Jason A. Gilliland 


\title{
If You Make it Free, Will They Come? Using a Physical Activity Accessibility Model to Understand the Use of a Free Children's Recreation Pass
}

\author{
Andrew F. Clark, Joannah Campbell, Patricia Tucker, Piotr Wilk, and Jason A. Gilliland
}

\begin{abstract}
Background: Children's sedentary lifestyles and low physical activity levels may be countered using population-level interventions. This study examines factors influencing the use of a free community-wide physical activity access pass for grade 5 students (G5AP). Methods: A natural experiment with longitudinal data collection. A sample of 881 children completed the 9-month follow-up survey self-reporting where they used the G5AP. Two analyses were conducted: Getis-Ord GI* geographic cluster analysis of the spatial distribution of users, and logistic regression examining the relationship between use and accessibility (informational, economic, and geographic) and mobility options, while accounting for intrapersonal and interpersonal factors. Results: Overall, 44.9\% of children used the G5AP with clusters of high use in urban areas and low use in the suburbs. Other factors significantly related to G5AP included gender (girls), informational accessibility (active recruitment), economic accessibility (median household income), geographic accessibility (facilities within $1.6 \mathrm{~km}$ of home), and mobility options (access to Boys \& Girls Club bus). Conclusions: This study found that a diverse population of children used the G5AP. To continue being successful, community-based physical activity interventions need to ensure that the intervention increases geographic, economic, and informational accessibility and provides mobility options that are available to the target population.
\end{abstract}

Keywords: interventions, youth, community-based research, health promotion

In recent decades, there has been a dramatic decline in child and youth physical activity (PA) levels. ${ }^{1,2}$ Only one-third of Canadian children aged 5-17 years are currently meeting the daily recommendations of an average of 60 minutes of moderate to vigorous PA per day,,$^{3,4}$ despite the well-documented health benefits of doing so. 5 These low rates of PA are similar to rates found throughout the world, with only 1 of 5 children aged $13-15$ years getting the recommended levels of PA. 6,7

Some community-based interventions have shown a limited capacity to change PA behavior, but most are still struggling to make change at a population level. ${ }^{8-11}$ The reason many interventions lead to no substantial change in PA is due to their inability to engage the subpopulations of children for whom the intervention is most needed. ${ }^{12-14}$ The existing literature has noted several key factors related to engagement in a PA intervention for children at multiple levels of the social-ecological framework: intrapersonal (eg, gender, ethnicity, existing PA levels), ${ }^{15-18}$ interpersonal (eg, socioeconomic status, social barriers), ${ }^{16,18-21}$ and physical environment (eg, distance to facility, seasonality). ${ }^{13,15,18,22-24}$ Despite these known factors related to participation, most research has not fully considered the role of accessibility when examining the engagement in a PA intervention. Accessibility is vital to understand, as the success of an intervention cannot be attained

Clark, Campbell, and Gilliland are with Human Environments Analysis Laboratory, Department of Geography, University of Western Ontario, London, Ontario, Canada. Clark, Campbell, Wilk, and Gilliland are with Children's Health Research Institute, London, Ontario, Canada. Tucker is with the School of Occupational Therapy, University of Western Ontario, London, Ontario, Canada. Wilk and Gilliland are with the Department of Epidemiology \& Biostatistics, and the Department of Paediatrics, University of Western Ontario, London, Ontario, Canada. Gilliland is also with the School of Health Studies, University of Western Ontario, London, Ontario, Canada. Gilliland (jgillila@uwo.ca) is corresponding author. if the target populations cannot access the opportunities being provided to them. ${ }^{25,26}$

This study focused on how factors identified by the socialecological framework influence the engagement in a communitybased access pass intervention for children's PA, through the lens of a PA accessibility model (see Figure 1). The accessibility to PA model combines 3 spheres that intersect to provide the degree to which a child has access to opportunities to be active: (1) information accessibility; (2) geographic accessibility; and (3) economic accessibility. The intersection of these 3 spheres also adds other aspects of accessibility, including mobility options (ie, geographic and economic), spatial awareness (ie, geographic and information), and opportunity awareness (ie, information and economic).

Information accessibility is defined as the amount and quality of information presented to intervention participants (and their parents) so that they are aware of the intervention, the location where the intervention is offered (and how to get there), and how to engage in the intervention. Recent literature has identified that participants who receive more information and advertisements about the intervention gain greater benefits to their health. ${ }^{27,28}$ This suggests that providing participants with increased information may also increase engagement in a PA intervention.

Geographic accessibility refers to the ability of a participant to get to the locations where the intervention is being offered. The literature has consistently found that geographic accessibility is significantly related to the ability to access PA opportunities and be active. ${ }^{25,29,30}$ Accessibility to PA opportunities is especially a concern for children who have limited independent mobility, ${ }^{31-34}$ which is exacerbated when parental support for PA is limited ${ }^{35}$ or when parents do not have a personal vehicle to take their child to PA facilities. As a result, if children, especially vulnerable groups of children (eg, low income, visible minority, recent immigrants), 
do not have easy geographic accessibility to intervention locations, they are unlikely to engage in a PA intervention.

Economic accessibility refers to the ability of participants to afford participating in the PA intervention. Although many interventions provide free access to programming, there are other costs related to PA participation, including transportation to and from the intervention locations $\mathrm{s}^{25,36,37}$ and proper equipment/attire to participate in the activity. ${ }^{38,39}$ Subsequently, if the intervention does not properly account for associated costs, engaging in the PA intervention will be difficult, especially for children from families with low socioeconomic status. ${ }^{16}$

While all 3 spheres are important to accessibility, mobility options can be the most impactful when developing a community-

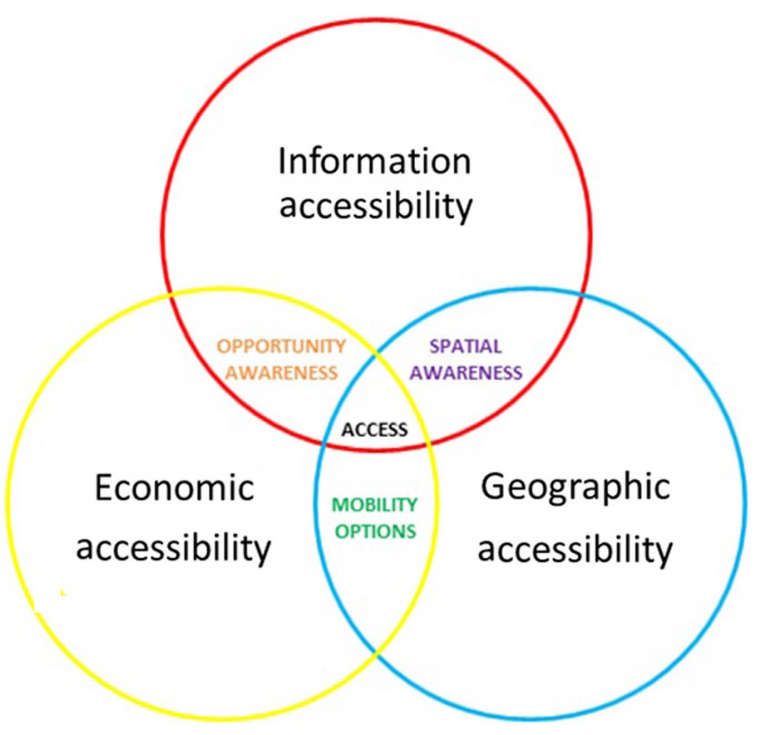

Figure 1 - Theoretical outline of the physical activity accessibility model. based PA intervention. ${ }^{25,36,37}$ Affordable mobility options provide children the ability to travel from their home or school to PA facilities to participate in the intervention. Research has shown that car ownership, public transportation, and special facility-specific transportation can all provide mobility options to allow children to access the intervention. . $^{25,36,37}$

The overall purpose of this study was to examine factors that influence children's use of the Grade 5 ACT-i-Pass (G5AP), a community-based PA intervention available to all grade 5 students residing or attending school in London, Ontario, a mid-sized Canadian city. ${ }^{14,40}$ The G5AP provided any registered user (plus one guest) free admission to drop-in and registered programs at 18 locations from 4 recreation service provider partners distributed across the city (see Figure 2 for a sample schedule of program offerings in spring 2015). The study attempted to answer 3 specific research questions:

1. How does use of the G5AP vary geographically across the study area?

2. How do intrapersonal and interpersonal factors influence use of the G5AP?

3. How does use of the G5AP relate to geographic accessibility, economic accessibility, informational accessibility, and mobility options?

\section{Methods}

This study was a natural experiment using a longitudinal study design to evaluate the factors related to use of the G5AP. A description of the intervention and full research project is available elsewhere. ${ }^{40}$ The research was approved by Western University's Non-Medical Research Ethics Board (REB\# 103954) and all 4 local school boards (2 English and 2 French boards). Parental consent and child assent were obtained for all participating children. Students were informed that participation in the research project part of the intervention was entirely optional and not a requirement for receiving the G5AP.

ACT-i-Pass 2015 Spring Schedule

\begin{tabular}{l|l|l|l|l|l|l|l|}
\hline \multicolumn{1}{|c|}{ MONDAY } & \multicolumn{1}{|c|}{ TUESDAY } & WEDNESDAY & \multicolumn{1}{|c|}{ THURSDAY } & \multicolumn{1}{c|}{ FRIDAY } & \multicolumn{1}{c|}{ SATURDAY } & \multicolumn{1}{c}{ SUNDAY } \\
\hline SKATING - Free entry to all public skating/family skating September through to the end of March at all City Facilities.
\end{tabular}

For more Information about ACT-i-Pass, visit

playeveryday.ca

Figure 2 - Sample ACT-i-Pass schedule. 


\section{Study Sample}

Grade 4 students from 98 out of 99 elementary schools within the city limits of London were recruited to register for the intervention. Schools were recruited through introductory e-mails to principals and follow-up phone calls, and, if a principal agreed, students were given packages to bring home to their parents/guardians, including program details, information about the research project, a parental consent form, and a parent survey. Children who received parental consent were asked to complete a baseline survey and 3 follow-up surveys (3, 9, and $12 \mathrm{mo}$ ). Children who registered for the intervention received their free access pass, along with information on how to use the pass, a schedule of programming, and facility locations. Passes were valid for the duration of the school year (September-June). The total sample of students registered for the G5AP program included 1709 students from the 3677 eligible students across the 99 schools. This study used data collected from the 9-month follow-up survey that was conducted just before the end of the intervention. The final data set included 881 participants from 99 schools.

\section{Measures}

Dependent Variables. The 5 dependent variables used in this study are self-reported measures of facility usage, which were collected on a youth survey delivered at 9 months after the start of the intervention: (1) overall use of the G5AP at any of the 18 facilities, (2) usage at 1 of the 3 YMCA facilities, (3) usage at the Boys \& Girls Club of London (BGCL), (4) usage at 1 of the 3 city pools, and (5) usage at 1 of the 11 city arenas. The variables are measured using a series of binary measures of usage, which are determined by a child stating they used the facility (1) or not (0).

Independent Variables. The primary independent variables of interest in this study are measures of accessibility (informational, economic, and geographic) and mobility options. Informational accessibility is measured as the degree to which the research team interacted with the participants. When the children were passively recruited (0) to participate in the study, their only contact with the research team was through the project website and letter of information sent home to parents. By contrast, the children who were actively recruited (1) received repeated reminders about the project, as the researchers conducted an engaging recruitment presentation and then went back to administer 4 surveys in person, during which time children could ask questions and get more information about the pass.

Although the G5AP provides free access to PA opportunities, there are still potential economic barriers surrounding paying for equipment to participate and the cost of traveling to and from the G5AP facility. Economic accessibility is measured by median household income (MHHI) in Canadian Dollars at the census dissemination area (DA) level based on the location of a child's postal code as a proxy of household income, which may influence whether a child can afford the appropriate equipment (eg, clothing, skates) and costs associated with travel to facilities to participate in G5AP activities.

Geographic accessibility is measured using a binary measure of accessibility identifying if each category of facility (ie, any facility, arenas, pools, YMCA, and BGCL) is located within $1.6 \mathrm{~km}$ of a child's home (1) or not (0). The distance between home and each G5AP facility was computed in ArcGIS 10.4 (Redlands, CA $)^{41}$ as the shortest network distance between a child's postal code, which was obtained from the parent survey, and each facility.
A $1.6-\mathrm{km}$ (or 1 mile) cutoff was used because it was considered by the local school boards to be a distance that an average elementary school child can walk.

The intersection between economic accessibility and geographic accessibility in the PA accessibility model is mobility options, which is measured as the modes of transportation available for a child to travel to and from a G5AP facility. Mobility options include vehicle ownership (no vehicles in main home [0]; vehicle in main home [1]) and bus pass ownership (no bus pass [0]; own bus pass [1]), and whether a school is a BGCL bus stop (1) or not (0). The BGCL bus stop refers to a bus service that children may ride unaccompanied (with parental consent) between designated schools and the BGCL every week throughout the school year.

To account for factors at the intrapersonal and interpersonal levels, as identified by the social-ecological framework, additional variables were also explored. Specifically, the youth survey collected self-reported responses for participants: gender (girl [0]; boy [1]), immigrant status (born in Canada [0]; born outside of Canada [1]), visible minority (Caucasian [0]; other ethnicities [1]), lone parent household (2 parents in main home [0]; 1 parent in main home [1]), and presence of siblings (no siblings [0]; 1 or more sibling [1]). Children also provided their perceptions of parental support ${ }^{35,42,43}$ and peer support. ${ }^{44}$ Parental support was measured on a scale ranging from 0 (low support) to 5 (high support) by averaging responses to 4 Likert-scale questions: (1) a parent/guardian watched you participate in PA or play sports, (2) a parent/guardian encouraged you to do sports or PA, (3) a parent/guardian provided transportation to a place where you can do PA or sports, and (4) a parent/guardian has done PA or played sports with you. Similarly, peer support was measured on a scale ranging from 0 to 5 by averaging responses to 4 Likert-scale questions: (1) your friends encouraged you to do sports or PA, (2) your friends do PA or play sports with you, (3) your friends or classmates tease you about not being good at PA or sports (reverse coded), and (4) your friends tell you that you are doing well in PAs or sports.

The parent survey provided the following self-report interpersonal variables: maternal and paternal education status (high school diploma or less [0]; graduating from a postsecondary institution [1]; and attaining a graduate degree [2]) and maternal and paternal employment status (unemployed, defined as unemployed, disability/parental leave, retired [0]; employed, defined as self-employed, part-time employment, and full-time employment [1]).

\section{Statistical Analysis}

Two data analysis techniques were employed to examine the 3 research questions: Getis-Ord GI* hot-spot analysis (question 1) and binary logistic regression (questions 2 and 3). Significant testing for all data analyses are based on $P$ values less than .05. Research question 1, to examine how G5AP use varies geographically across the study area, was conducted using the Getis-Ord GI* hot-spot analysis, which measures spatial autocorrelation, or spatial clustering, of aerial units with high and low usage rates across the study area. Usage rates are calculated by dividing the number of children who used the pass at any facility by the total number of children registered in the G5AP for each census DA, the smallest geographic unit in which socioeconomic data are released. ${ }^{45}$ The analysis was conducted in ArcMap 10.4 (Redlands, CA) ${ }^{41}$ by comparing usage rates in each DA with those in surrounding DAs to identify statistically significant high or low values compared with the overall average within $250 \mathrm{~m}$. The results of this analysis are interpreted as a $z$ score and provide evidence on how 
usage rates at the DA level are clustered around high and low values (hot and cold spots).

Research questions 2 and 3, examining the individual, intrapersonal, and accessibility factors related to G5AP use, are analyzed using a series of multilevel logistic regression models to assess the presence of a relationship between geographic accessibility to recreation facilities and use of the G5AP, while accounting for factors at the intrapersonal and interpersonal levels. Multilevel models are used to account for children being clustered within the elementary school they attend. The models in this study are estimated based on the following generic model:

$$
W_{i j}=\beta_{0}+\beta_{1 j} X_{i j}+\mu_{0 j},
$$

where $i$ represents the $i$ th child, $j$ represents the $j$ th school, $W_{i j}$ represents the usage of the location ith child from a $j$ th school, $\beta_{0}$ refers to the intercept of the dependent variables in the model, $\beta_{1 j}$ is the intercept for a child-level independent variable, $X_{i j}$ represents a value for child-level independent variables, and $\mu_{0 j}$ is the unexplained random intercept variance or between-school variance. Five models were run for this analysis based on the types of facilities that were used: (1) any facilities, (2) arenas, (3) pools; (4) YMCA, and (5) BGCL. The data cleaning was performed using IBM Statistical Package for Social Science (SPSS, v22; Chicago, IL) software, ${ }^{46}$ and subsequent statistical analyses were performed using STATA SE 13 (College Station, TX). ${ }^{47}$

\section{Results}

Descriptive statistics describing the population are outlined in Table 1. There was an even distribution of boys (45.1\%) and girls $(46.2 \%)$, with one-third $(33.1 \%)$ of the students identifying as a visible minority. The profile of the children/parents show that most participants had sibling(s) at home (88.0\%) and $15.4 \%$ were from lone parent households. Children with high informational accessibility due to being actively recruited represented $70.1 \%$ of participants. Almost all of the participants owned at least 1 vehicle $(85.0 \%)$, with only $14.1 \%$ of participants reporting a family member owning a bus pass, which may limit the mobility options of participating children. With respect to the geographic accessibility, one-third of the sample lived within $1.6 \mathrm{~km}$ of any G5AP facility, with arenas being the most frequently located within $1.6 \mathrm{~km}(24.0 \%)$, as they are most widely distributed. All other facility types were less accessible, with less than $10 \%$ of participants living within $1.6 \mathrm{~km}$. Just under half of the participants (44.9\%) reported that they used the G5AP throughout the study, with the City of London pools being the most frequently used location $(38.3 \%)$ and YMCA being the least frequently used location $(15.0 \%)$.

\section{Spatial Clustering Analysis}

The G5AP facilities and usage rates by census DA are shown in Figure 3. The G5AP facilities are indicated with a green point and are fairly distributed throughout the city, with slightly more facilities available for participants in the core. The lightest shade represents the lowest usage rates, and the darkest shades represent the highest usage rates, with DAs with no G5AP registration identified in white. The distribution of usage seems to be scattered throughout the city, with areas close to G5AP facilities having little relation to high usage rates.

Results from the Getis-Ord GI*, as seen in Figure 4, show locations of significant clustering throughout the city with cold spots (blue) representing significant clustering of low usage rates and hot spots (red) representing significant clustering of high usage rates. The cold spots are in the southwest quadrant of the city, where there is very low accessibility to any G5AP facilities offered as part of the intervention. The westernmost cold spot is isolated from the rest of the city as well, with limited infrastructure to get children from the suburban neighborhood to the core. The primary hot spot identified is in the core of the city, which is close to multiple facilities within walking distance (eg, BGCL, YCMA, arenas). There is also extensive transportation infrastructure throughout this area, making it easy to get out of the core into other parts of the city without having to own a car.

\section{Logistic Regression Analysis}

The results of the 5 models are presented in Table 2. The results of model 1, examining use of the G5AP at any of the 18 facilities, showed 4 variables significantly related to children using the G5AP: recruitment type, MHHI, gender, and parental support. Informational accessibility was found to be important when accessing any of the facilities, with children significantly more likely to use the G5AP when actively recruited (odds ratio $[\mathrm{OR}]=1.733$; $P=.01$ ). Economic accessibility, as measured by MHHI, was found to be negatively associated with use of the G5AP with children living in higher income neighborhoods, showing that children from lower income neighborhoods are more likely to use the G5AP ( $\mathrm{OR}=0.934 ; P=.04)$. Finally, girls $(\mathrm{OR}=0.689$; $P=.02)$ and children with high levels of parental support $(\mathrm{OR}=1.161 ; P<.01)$ were significantly more likely to use the G5AP at any of the facilities included in the program.

The results of model 2 revealed a significant relationship between the use of the G5AP at any of the 11 arenas included in the program and geographic accessibility, gender, visible minority, and parental support. Geographic accessibility is related to an increase in the use of arenas, with children living within $1.6 \mathrm{~km}$ of an arena significantly more likely to use their G5AP for skating $(\mathrm{OR}=1.581 ; P=.03)$. Children with higher parental support $(\mathrm{OR}=1.141 ; P=.01)$ and children who identify as Caucasian $(\mathrm{OR}=0.620 ; P=.02)$ are significantly more likely to use the G5AP at an arena.

Model 3 found only 2 factors related to the use of G5AP at the 3 pools included in the program: gender and paternal employment status. Girls are significantly related to an increase in the odds of using the G5AP at pools compared with boys $(\mathrm{OR}=0.669 ; P=.01)$. Similarly, children with employed fathers were significantly more likely to use their pass to swim at pools than children whose fathers were unemployed $(\mathrm{OR}=1.788$; $P=.03$ ).

Model 4 shows that informational accessibility, mobility options, and living in a 2-parent household are related to increased use of the G5AP at the YMCA. Informational accessibility showed children recruited actively were significantly more likely to use the G5AP at the YMCA than children who were recruited passively $(\mathrm{OR}=1.764 ; P=.09)$. Mobility options are minimized in this model, with car ownership being negatively associated with use at the YMCA; children whose parents do not have a car were more likely to use the pass $(\mathrm{OR}=0.320 ; P=.01)$. Finally, children living in lone parent households were significantly less likely to use their G5AP at the YMCA than children who were living in a 2-parent household $(\mathrm{OR}=0.467 ; P=.03)$.

Finally, model 5 examined the use of the G5AP at the BGCL and found usage was related to informational accessibility, 
Table 1 Descriptive Statistics of Dependent and Independent Variables Used in This Study $(\mathrm{N}=\mathbf{8 8 1})$

\begin{tabular}{|c|c|}
\hline Variables & Descriptive statistics \\
\hline \multicolumn{2}{|l|}{ Dependent variables } \\
\hline Use ACT-i-Pass, n (\%) & $388(44.9)$ \\
\hline Use ACT-i-Pass at the Boys \& Girls Club, n (\%) & $156(18.0)$ \\
\hline Use ACT-i-Pass at a City of London arena, n (\%) & $196(22.7)$ \\
\hline Use ACT-i-Pass at a YMCA, n (\%) & $130(15.0)$ \\
\hline Use ACT-i-Pass at a City of London pool, n (\%) & $331(38.3)$ \\
\hline \multicolumn{2}{|l|}{ Independent variables } \\
\hline \multicolumn{2}{|l|}{ Informational accessibility } \\
\hline Active recruitment, $\mathrm{n}(\%)$ & $606(70.1)$ \\
\hline \multicolumn{2}{|l|}{ Economic accessibility } \\
\hline Median household income in $\$ 10,000 \mathrm{CAD}$, mean (SD) & $6.75(2.55)$ \\
\hline \multicolumn{2}{|l|}{ Mobility options } \\
\hline Car in household, $\mathrm{n}(\%)$ & $709(82.0)$ \\
\hline London transit bus pass ownership, $\mathrm{n}(\%)$ & $122(14.1)$ \\
\hline Attend a school with Boys \& Girls Club bus stop, n (\%) & $155(17.9)$ \\
\hline \multicolumn{2}{|l|}{ Geographic accessibility } \\
\hline Live within $1.6 \mathrm{~km}$ of any ACT-i-Pass facility, $\mathrm{n}(\%)$ & $295(34.1)$ \\
\hline Live within $1.6 \mathrm{~km}$ of a City of London arena, $\mathrm{n}(\%)$ & $208(24.0)$ \\
\hline Live within $1.6 \mathrm{~km}$ of a City of London pool, n (\%) & $69(8.0)$ \\
\hline Live within $1.6 \mathrm{~km}$ of a YMCA location, $\mathrm{n}(\%)$ & $50(5.8)$ \\
\hline Live within $1.6 \mathrm{~km}$ of London's Boys \& Girls Club, n (\%) & $21(2.4)$ \\
\hline \multicolumn{2}{|l|}{ Intrapersonal } \\
\hline \multicolumn{2}{|l|}{ Gender, n (\%) } \\
\hline Girl & $400(46.2)$ \\
\hline Boy & $390(45.1)$ \\
\hline Visible minority, $\mathrm{n}(\%)$ & $286(33.1)$ \\
\hline Immigrated to Canada, n (\%) & $89(10.3)$ \\
\hline \multicolumn{2}{|l|}{ Interpersonal } \\
\hline Lone parent household, n (\%) & $133(15.4)$ \\
\hline Siblings present in household, $\mathrm{n}(\%)$ & $735(85.0)$ \\
\hline \multicolumn{2}{|l|}{ Mother's education status, n (\%) } \\
\hline High school diploma or less & $136(15.7)$ \\
\hline College/university or more & $640(74.0)$ \\
\hline \multicolumn{2}{|l|}{ Father's education status, n (\%) } \\
\hline High school diploma or less & $186(21.5)$ \\
\hline College/university or more & $557(64.4)$ \\
\hline \multicolumn{2}{|l|}{ Mother's occupation status, n (\%) } \\
\hline Employed & $649(63.5)$ \\
\hline Unemployed & $112(12.9)$ \\
\hline \multicolumn{2}{|l|}{ Father's occupation status } \\
\hline Employed, n (\%) & $649(63.5)$ \\
\hline Unemployed, n (\%) & $112(12.9)$ \\
\hline Parental support, mean (SD) & $3.65(2.04)$ \\
\hline Peer support, mean (SD) & $4.29(1.58)$ \\
\hline
\end{tabular}

economic accessibility, mobility options, and the father's education. Specifically, children who were actively recruited using the G5AP frequented the BGCL significantly more than those who were passively recruited $(\mathrm{OR}=1.880 ; P=.04)$. In addition, children living in a neighborhood with low $\mathrm{MHHI}(\mathrm{OR}=0.897$; $P=.02$ ) were significantly more likely to use the G5AP at the
BGCL. G5AP use at the BGCL was also associated with mobility options, where children attending a school that has a BGL bus stop $(\mathrm{OR}=2.081 ; P=.02)$ were significantly more likely to use the G5AP at the BGCL. Finally, children whose fathers had low educational attainment $(\mathrm{OR}=0.439 ; P=.001)$ were significantly more likely to visit the BGCL to use their G5AP. 


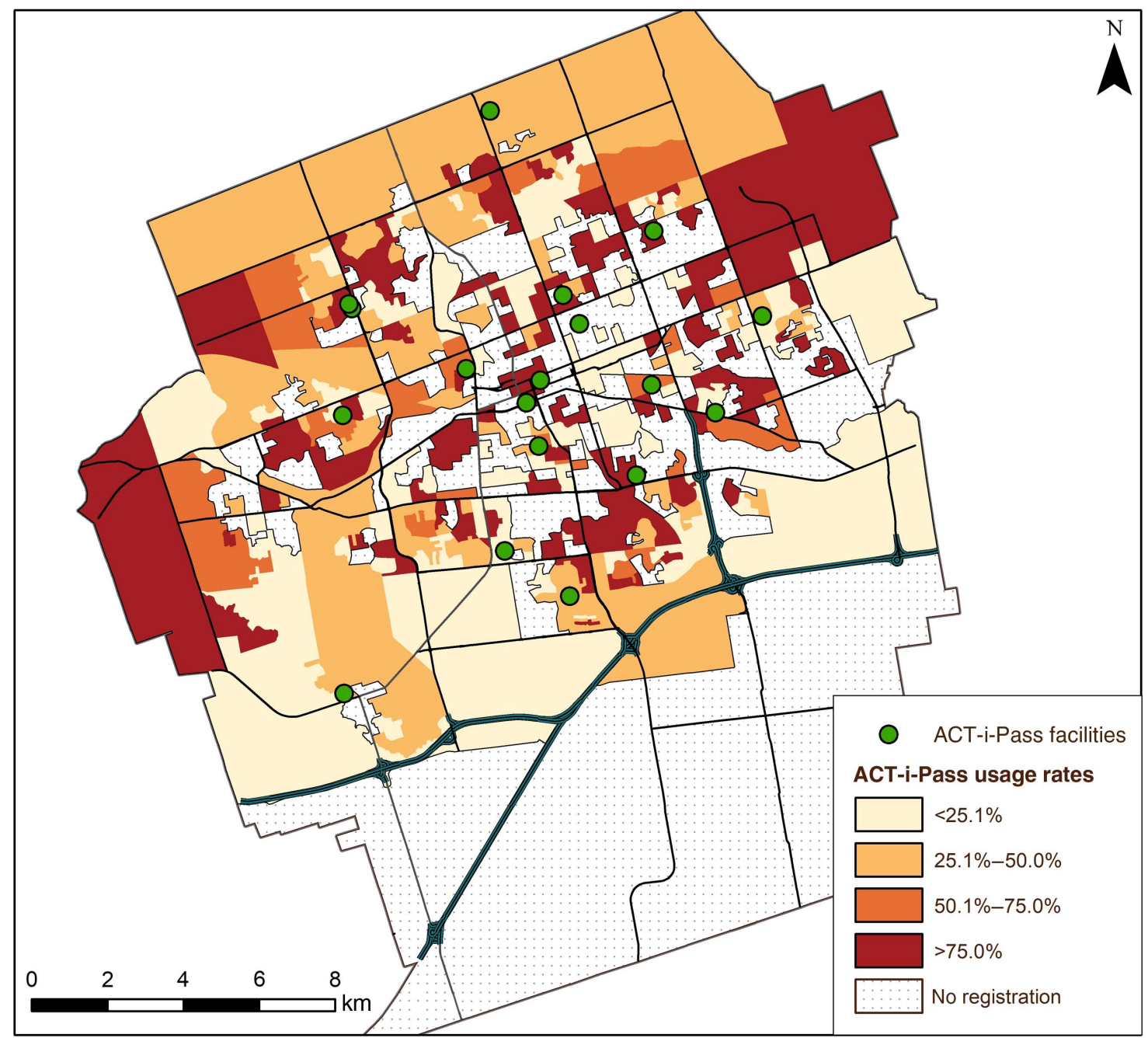

Figure 3 - Usage rates for the Grade 5 ACT-i-Pass program by dissemination area in London, Ontario, Canada.

\section{Discussion}

This study examined factors that influence children's engagement and use of the G5AP throughout the City of London, Ontario, Canada by addressing 3 key research questions. The first examines how the use of the G5AP varies geographically across the study area, the second examines how the use of the G5AP varies according to factors at the intrapersonal and interpersonal levels, and the third examines how the use of the G5AP varies based on informational, economic, and geographic accessibility, as well as mobility options. Overall, $44.9 \%$ of children used the G5AP throughout the study period and, as with registration, ${ }^{14}$ there seems to be an inequality among the children who use the pass. Spatial cluster analysis shows hot spots of high and low G5AP usage across the city, and regression analysis highlights subgroups of the population that are more likely to use the G5AP. Despite this inequality, the children who are commonly found to have barriers to PA (eg, girls, children with low-economic accessibility, geographic accessibility, and mobility options) seem to be G5AP users, suggesting some of the common accessibility barriers may be overcome by this intervention.

There are a variety of intrapersonal and interpersonal factors that have been found to be significantly related to G5AP use, including intrapersonal (eg, gender, visible minority) and interpersonal (eg, paternal employment status, parental support) factors. Visible minorities are significantly less likely to use their G5AP at an arena than their white counterparts, which, as previous literature suggests, ${ }^{48}$ may be a result of cultural differences in PA preferences and behaviors. Children with fathers who have lower levels of education (ie, high school diploma or less) are also more likely to use the G5AP at the BGCL. This finding may be a result of their organization's mission of promoting inclusivity by offering affordable and supportive recreation opportunities to all children and families in the community, regardless of background or socioeconomic status. ${ }^{49}$ Many of these factors are also associated with groups of children who were frequently found to have low levels of PA and engagement in previous studies, ${ }^{15-17}$ including girls and children with low parental support. Girls were found to be significantly more likely to use the pass at any G5AP facility than boys, as well as specifically at a pool. If a free recreation pass can encourage girls to be more active, it provides a model in which health promoters may be able to decrease the gap between boys' and girls' PA levels. ${ }^{25,50}$ Girls' preference of swimming is also positive to see, as many cities across Canada already offer sponsored free swims at designated times throughout the summer months, allowing children of all ages to swim for free at all public pools. 


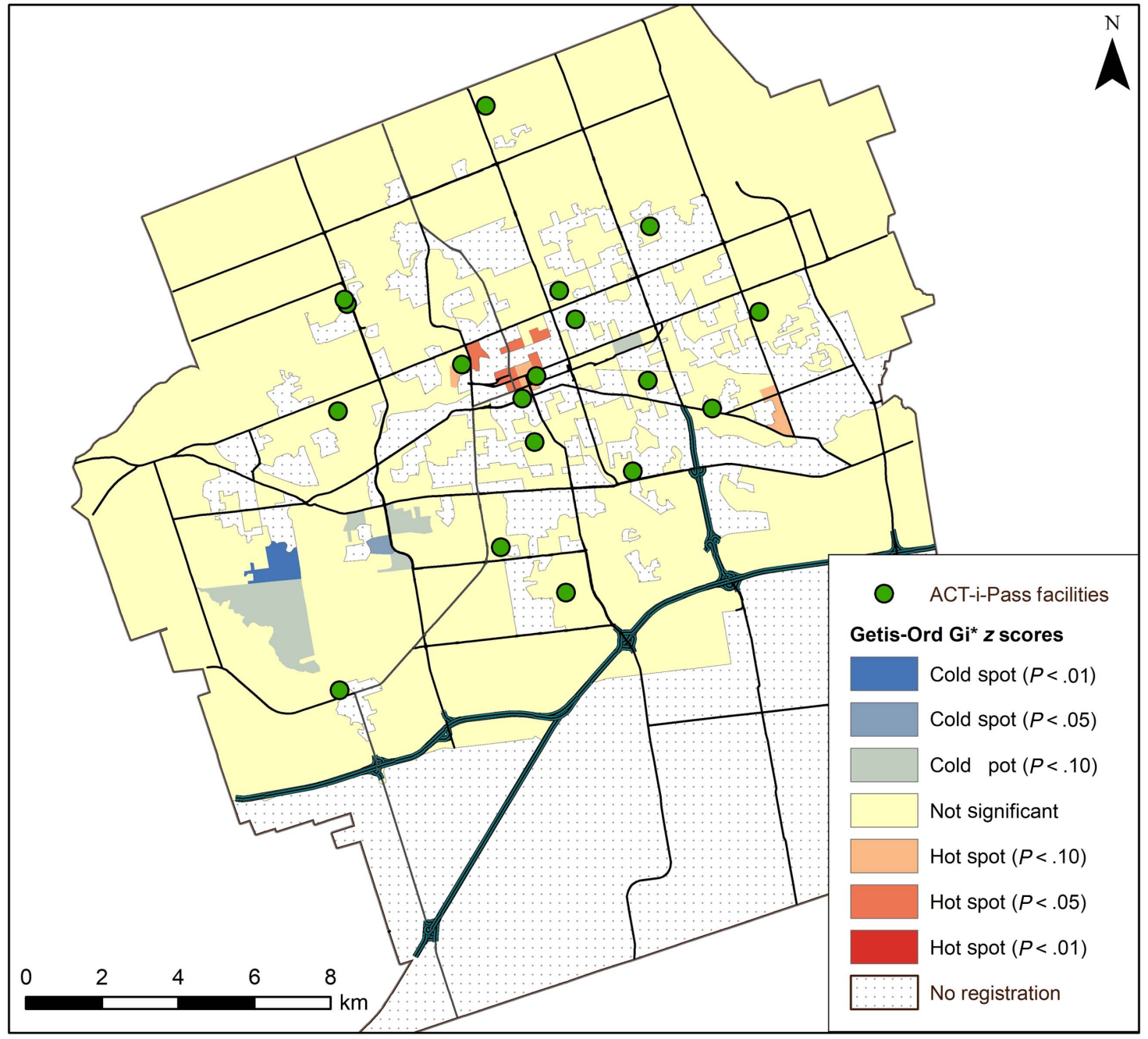

Figure 4 - Results of the Getis-Ord GI* hot- and cold-spot analysis of Grade 5 ACT-i-Pass usage rates in London, Ontario, Canada.

Parental support for PA is another key factor related to increased use, where children who have higher parental support are significantly more likely to use their G5AP at any facility or arena. This is consistent with previous studies suggesting that parental support is the key for engagement in a PA intervention, ${ }^{16}$ as well as PA in general. ${ }^{35,43}$ By contrast, low parental support just misses being significantly related to use at the BGCL, which provides a free bus to take children (with parental consent) from specific schools in low-income neighborhoods once per week unaccompanied by a parent/guardian. This suggests that future interventions may be able to overcome parental support as a barrier if they offer access to facilities without needing parents to transport their children.

Although this study shows that the G5AP intervention may be able to engage children who have lower levels of PA, we also were able to evaluate the effectiveness of the G5AP to increase the accessibility to PA opportunities as defined by the PA accessibility model. Increasing the informational accessibility by actively recruiting children to register for the G5AP was incredibly important for both registration ${ }^{14}$ and usage of the G5AP. Each time the research staff visited schools, they explained the program and answered any questions, which provided additional information about how to use the pass at different facilities and some of the unadvertised perks associated with the pass (eg, BGCL bus). Providing this additional information was found to significantly increase the use of the pass in general, as well as at the YMCA and BGCL where registration and admission were a little more complicated (eg, children need to register a second time to sign waivers to use the facility).

Despite the G5AP providing free access to recreational facilities across London, there are still financial barriers for children to use the G5AP, such as equipment to participate (eg, skates, swimsuits, proper footwear) and mobility options. ${ }^{25,36-39}$ The results show that G5AP has been successful at overcoming economic accessibility, as the odds of overall use and use of the G5AP at the BGCL increase significantly as neighborhood MHHI decreases. Providing a free pass to the entire population can increase PA opportunities for those in low-income neighborhoods without the stigmatization associated with a family registering for a discount program. ${ }^{51}$ Variables associated with mobility options suggest that there is no strong correlation with travel to a facility, as owning a car is negatively associated with G5AP use at the YMCAs that are centrally located. Finally, attending a school with a BGCL bus stop significantly increases the chances that a child will use the BGCL, which helps overcome the mobility barriers to children who attend those schools. 
Table 2 Results of Multilevel Binary Logistic Models Examining How ACT-i-Pass Usage is Influenced by Factors at the Intrapersonal, Interpersonal, and Physical Environment Levels

\begin{tabular}{|c|c|c|c|c|c|c|c|c|c|c|}
\hline & \multicolumn{2}{|c|}{$\begin{array}{l}\text { Model 1: any } \\
\text { facilities }\end{array}$} & \multicolumn{2}{|c|}{ Model 2: arenas } & \multicolumn{2}{|c|}{ Model 3: pools } & \multicolumn{2}{|c|}{ Model 4: YMCA } & \multicolumn{2}{|c|}{$\begin{array}{l}\text { Model 5: Boys \& } \\
\text { Girls Club }\end{array}$} \\
\hline & OR (SE) & $P$ & OR (SE) & $\boldsymbol{P}$ & OR (SE) & $\boldsymbol{P}$ & OR (SE) & $\boldsymbol{P}$ & OR (SE) & $\boldsymbol{P}$ \\
\hline Constant & $0.581(0.363)$ & .39 & $0.059(0.045)$ & $.000 *$ & $0.482(0.308)$ & .25 & $0.513(0.404)$ & .40 & $0.337(0.270)$ & .18 \\
\hline \multicolumn{11}{|l|}{ Intrapersonal variables } \\
\hline Boy (ref: girl) & $0.689(0.106)$ & $.02 *$ & $1.383(0.252)$ & .08 & $0.669(0.108)$ & $.01 *$ & $0.909(0.197)$ & .66 & $0.936(0.195)$ & .75 \\
\hline Visible minority (ref: Caucasian) & $0.968(0.167)$ & .85 & $0.620(0.131)$ & $.02 *$ & $0.939(0.169)$ & .73 & $1.248(0.299)$ & .36 & $0.918(0.217)$ & .72 \\
\hline Immigrant status (ref: born in Canada) & $0.951(0.253)$ & .85 & $0.764(0.262)$ & .43 & $0.989(0.279)$ & .97 & $1.493(0.493)$ & .23 & $1.428(0.478)$ & .29 \\
\hline \multicolumn{11}{|l|}{ Interpersonal variables } \\
\hline Lone parent household (ref: 2 parents) & $1.183(0.253)$ & .43 & $1.196(0.304)$ & .48 & $1.398(0.311)$ & .13 & $0.467(0.159)$ & $.03 *$ & $1.151(0.315)$ & .61 \\
\hline Siblings (ref: only child) & $0.608(0.197)$ & .13 & $0.743(0.273)$ & .42 & $0.650(0.219)$ & .20 & $0.556(0.230)$ & .16 & $1.127(0.507)$ & .79 \\
\hline $\begin{array}{l}\text { Mother has college/university (ref: } \\
\text { high school diploma or less) }\end{array}$ & $1.263(0.283)$ & .30 & $1.529(0.442)$ & .14 & $0.738(0.171)$ & .19 & $0.961(0.297)$ & .90 & $1.513(0.435)$ & .15 \\
\hline $\begin{array}{l}\text { Father has college/university (ref: } \\
\text { high school diploma or less) }\end{array}$ & $0.800(0.159)$ & .26 & $1.150(0.277)$ & .56 & $1.180(0.250)$ & .43 & $0.767(0.215)$ & .34 & $0.439(0.109)$ & $<.01 *$ \\
\hline Mother employed (ref: unemployed) & $1.052(0.173)$ & .76 & $0.930(0.180)$ & .71 & $1.020(0.175)$ & .91 & $0.843(0.198)$ & .47 & $0.763(0.169)$ & .22 \\
\hline Father employed (ref: unemployed) & $1.165(0.285)$ & .53 & $0.761(0.218)$ & .34 & $1.788(0.483)$ & $.03 *$ & $1.279(0.434)$ & .47 & $1.263(0.390)$ & .45 \\
\hline Parental support & $1.161(0.050)$ & $<.01 *$ & $1.141(0.057)$ & $.01 *$ & $1.024(0.046)$ & .61 & $1.031(0.062)$ & .61 & $0.893(0.052)$ & .05 \\
\hline Peer support & $0.982(0.054)$ & .74 & $0.946(0.062)$ & .40 & $1.009(0.059)$ & .87 & $1.077(0.084)$ & .34 & $1.142(0.085)$ & .08 \\
\hline \multicolumn{11}{|l|}{ Informational accessibility } \\
\hline Recruitment type (ref: passive) & $1.733(0.364)$ & $.01 *$ & $1.284(0.304)$ & .29 & $1.339(0.338)$ & .25 & $1.764(0.589)$ & .09 & $1.880(0.574)$ & $.04 *$ \\
\hline \multicolumn{11}{|l|}{ Economic accessibility } \\
\hline $\begin{array}{l}\text { Median household income } \\
(\$ 10,000 \mathrm{CAD})\end{array}$ & $0.934(0.031)$ & $.04 *$ & $1.032(0.038)$ & .39 & $1.007(0.035)$ & .84 & $0.955(0.045)$ & .32 & $0.897(0.043)$ & $.02 *$ \\
\hline \multicolumn{11}{|l|}{ Mobility options } \\
\hline Car ownership (ref: no car) & $1.313(0.477)$ & .45 & $2.309(1.215)$ & .11 & $1.044(0.391)$ & .91 & $0.320(0.137)$ & $.01 *$ & $0.589(0.248)$ & .21 \\
\hline $\begin{array}{l}\text { London transit bus pass } \\
\text { (ref: no bus pass) }\end{array}$ & $0.810(0.177)$ & .33 & $0.910(0.243)$ & .72 & $1.083(0.245)$ & .73 & $1.113(0.319)$ & .71 & $0.858(0.246)$ & .59 \\
\hline $\begin{array}{l}\text { Attend a school with Boys \& Girls } \\
\text { Club bus stop }\end{array}$ & $1.245(0.275)$ & .32 & & & & & & & $2.081(0.631)$ & $.02 *$ \\
\hline \multicolumn{11}{|l|}{ Geographic accessibility } \\
\hline $\begin{array}{l}\text { Live within } 1.6 \mathrm{~km} \text { of any ACT-i-Pass } \\
\text { facility }\end{array}$ & $1.141(0.188)$ & .42 & & & & & & & & \\
\hline $\begin{array}{l}\text { Live within } 1.6 \mathrm{~km} \text { of a City of } \\
\text { London arena }\end{array}$ & & & $1.581(0.326)$ & $.03 *$ & & & & & & \\
\hline $\begin{array}{l}\text { Live within } 1.6 \mathrm{~km} \text { of a City of } \\
\text { London pool }\end{array}$ & & & & & $0.660(0.215)$ & .20 & & & & \\
\hline $\begin{array}{l}\text { Live within } 1.6 \mathrm{~km} \text { of a YMCA } \\
\text { location }\end{array}$ & & & & & & & $2.264(0.949)$ & .05 & & \\
\hline $\begin{array}{l}\text { Live within } 1.6 \mathrm{~km} \text { of London's Boys } \\
\& \text { Girls Club }\end{array}$ & & & & & & & & & $0.641(0.455)$ & .53 \\
\hline Between-school variance (SE) & \multicolumn{2}{|c|}{$0.042(0.070)$} & \multicolumn{2}{|c|}{$0.047(0.092)$} & \multicolumn{2}{|c|}{$0.254(0.127)$} & \multicolumn{2}{|c|}{$0.272(0.188)$} & \multicolumn{2}{|c|}{$0.171(0.049)$} \\
\hline Pseudo log likelihood & \multicolumn{2}{|c|}{-564.161} & \multicolumn{2}{|l|}{-439.817} & \multicolumn{2}{|l|}{-547.870} & \multicolumn{2}{|l|}{-345.010} & \multicolumn{2}{|l|}{-368.408} \\
\hline
\end{tabular}

Abbreviation: OR, odds ratio.

Geographic accessibility is a known barrier to children being active, ${ }^{21,25,29,30}$ as children who are unable to get to a PA opportunity (eg, arena, recreation center) may not have anywhere they can be active. As a result, a large focus of this study was examining the impact of geographic accessibility in use. The spatial analysis of identifying hot and cold spots of use provided evidence that usage of the G5AP is not equal across the city, similar to findings related to registration reported elsewhere. ${ }^{14}$ The clustering is related to geographic accessibility of G5AP facilities, as hot spots are centrally located close to multiple types of facilities, whereas the cold spots have only one facility nearby. Modeling of geographic accessibility is also found to be related to use of G5AP, with having an arena and YMCA within $1.6 \mathrm{~km}$ of a child's home significantly increasing the opportunity of using the pass, although accessibility is not related to general use, pools, or BGCL. The relationship between G5AP use at the BGCL and geographical accessibility is 
minimized by attending a school with a BGCL bus stop, as it eliminates the impact of distance on children who attend bus stop schools.

Overall, this study provides many lessons to health promoters when developing interventions. First, knowing the population that the intervention is targeting ensures that the intervention can be customized to engage that population. In this study, the G5AP engaged girls and children living in low-income neighborhoods. By contrast, the G5AP failed to engage visible minorities and children with low parental support, suggesting more work needs to be done to increase the accessibility of the program.

The evidence health promoters can use to increase accessibility of the program is found in the examination of accessibility. Providing free transportation, such as what is done by the BGCL bus, can significantly increase the reach and economic accessibility of a child to PA programming. Although not every service provider has a fleet of buses, it may be possible to combine a free recreation pass with free public transportation opportunities to increase the ability of children to access the opportunities. If transportation cannot be provided, increasing the geographical accessibility by providing additional opportunities closer to where children live may be enough to engage children, as evident by variables examining geographic accessibility in this study. One such opportunity is to provide free programming or services in schools or local parks, which are more evenly distributed across the city. Finally, increasing informational accessibility of a program to a child and their parents through active recruitment and reminders can have a significant impact on the use of an intervention. Interaction with parents and children could be done through in-person recruitment presentations, as done in this study, or if resources are limited, by connecting with parents and children through newsletters, videos, and social media. If health promoters can find ways to increase the accessibility of an intervention and PA opportunities to a child, a child is more likely to engage in an activity and more likely to have higher levels of PA.

\section{Limitations}

There are a few key limitations in this study. First, usage data were self-reported by participants. This study attempted to collect objective measurements of usage, but the 3 different service providers with unique registration software, combined with parttime staff who change frequently, resulted in unreliable data that could not be used in analysis. Second, usage data were not associated with actual PA levels, but future research will examine the influence the G5AP has on children's PA levels over time. Third, we are unable to determine if the free G5AP is substitutive or additive to a child's overall PA behaviors, although future qualitative research with children may help identify how the G5AP alters their existing activities. Fourth, using postal code centroids to represent a child's home location allowed for additional anonymity in the data set, but they do not provide an exact home location. Despite this inaccuracy, Healy and Gilliland ${ }^{52}$ suggest that this is acceptable, as only minor inaccuracies are introduced when using postal codes as a proxy in urban centers.

\section{Conclusions}

Providing grade 5 children (aged 9-11 y) with free access to PA opportunities can provide an excellent opportunity for children to access facilities in support of their recommended 60 minutes of moderate to vigorous PA every day, but to benefit children, they need to be able to use the pass. This evaluation of the G5AP shows that many of the children who need the pass, such as girls and children with low accessibility, have been able to use it, thus increasing the chances that they gain the health benefits of the intervention. In particular, providing children with an access pass can increase the economic accessibility and allow children to access facilities for free without the stigmatizing experience that families get while trying to prove they meet a low-income threshold to receive discount rates. Future PA interventions need to develop their programs to ensure the target population engages in the intervention by increasing the information available to participants, while decreasing the barriers associated with economic accessibility, geographic accessibility, and mobility options.

\section{Acknowledgments}

The authors would like to thank their ACT-i-Pass project partners from London's Child \& Youth Network, Boys \& Girls Club London, YMCA of Western Ontario, the City of London Recreation Department, Thames Valley District School Board, London District Catholic School Board, and Montessori Academy of London. They are especially grateful for the leadership from Josh Archer (City of London), Nadine Harrison (BGCL), Chris Harvey (BGCL), David Inglis (Thames Valley District School Board), Tony Kyle (City of London), Sue McMahon (London District School Board), and the rest of the ACT-i-Pass working group for working with them to evaluate the ACT-i-Pass program. They would also thank fieldwork leaders (Sabrina Sater, Christine Smith, and Christine Mitchell) and more than 20 additional undergraduate research assistants. Finally, they are grateful to the staff of participating schools and school boards, as well as the children and their parents who are participating in the project. Research funding for this project was provided by the Canadian Cancer Society (grant \# 703083) and Canadian Institutes of Health ResearchInstitute for Population and Public Health for project funding (CIHR Grant \#322703 and \#327369). Additional funding was also provided by London's Child \& Youth Network, the Ontario Sport and Recreation Community Fund, and Children's Health Research Institute and Children's Health Foundation.

\section{References}

1. Quinney A, Tremblay M, Brownrigg M. Canada's report card on physical activity for children and youth. J Sci Med Sport. 2010;12: e72-e73. doi:10.1016/j.jsams.2009.10.149

2. Janssen I, Leblanc AG. Systematic review of the health benefits of physical activity and fitness in school-aged children and youth. Int $J$ Behav Nutr Phys Act. 2010;7:40. doi:10.1186/1479-5868-7-40

3. Colley R, Carson V, Garriguet D, Janssen I, Roberts K, Tremblay M. Physical activity of Canadian children and youth, 2007 to 2015. Health Rep. 2017;28(10):8-16. https://www150.statcan.gc.ca/n1/en/ pub/82-003-x/2017010/article/54876-eng.pdf?st=VVLEuPRL

4. Statistics Canada. Directly measured physical activity of children and youth, 2012 and 2013: results from the Canadian health measures survey. http://www.statcan.gc.ca/pub/82-625-x/2015001/article/14136eng.htm. Published 2015. Accessed January 2, 2019.

5. Barnes JD, Colley RC, Tremblay MS. Results from the Active Healthy Kids Canada 2011 report card on physical activity for children and youth. Appl Physiol Nutr Metab. 2012;37:793-797. PubMed ID: 22554118 doi:10.1139/h2012-033

6. Hallal PC, Andersen LB, Bull FC, et al. Global physical activity levels: surveillance progress, pitfalls, and prospects. Lancet. 2012; 380(9838):247-257. doi:10.1016/S0140-6736(12)60646-1 
7. Tremblay MS, Barnes JD, González SA, et al. Global matrix 2.0: report card grades on the physical activity of children and youth comparing 38 countries. J Phys Act Health. 2016;13(11 suppl 2): S343-S366. doi:10.1123/jpah.2016-0594

8. Kahn EB, Ramsey LT, Brownson RC, et al. The effectiveness of interventions to increase physical activity. A systematic review. Am J Prev Med. 2002;22(4 suppl):73-107. doi:10.1111/j.1553-2712.2011. 01127.x

9. Baker PRA, Francis DP, Soares J, Weightman AL, Foster C. Community wide interventions for increasing physical activity. Sao Paulo Med J. 2011;129(6):436-437. doi:10.1590/S151631802011000600013

10. Hillier-Brown FC, Bambra CL, Cairns J-M, Kasim A, Moore HJ, Summerbell CD. A systematic review of the effectiveness of individual, community and societal level interventions at reducing socioeconomic inequalities in obesity amongst children. BMC Public Health. 2014;14(1):834. doi:10.1186/1471-2458-14-834

11. van Sluijs EMF, Kriemler S, McMinn AM. The effect of community and family interventions on young people's physical activity levels: a review of reviews and updated systematic review. Br J Sports Med. 2011;45(11):914-922. PubMed ID: 21836175 doi:10.1136/bjsports2011-090187

12. Salmon J, Booth ML, Phongsavan P, Murphy N, Timperio A. Promoting physical activity participation among children and adolescents. Epidemiol Rev. 2007;29(1):144-159. doi:10.1093/epirev/ mxm010

13. Jago R, Baranowski T. Non-curricular approaches for increasing physical activity in youth: a review. Prev Med. 2004;39(1):157163. doi:10.1016/j.ypmed.2004.01.014

14. Clark AF, Wilk P, Mitchell CA, Smith C, Archer J, Gilliland JA. Examining how neighborhood socioeconomic status, geographic accessibility, and informational accessibility influence the uptake of a free population-level physical activity intervention for children. Am J Health Promot. 32(2):315-324. doi:10.1177/0890117117718433

15. Audrey S, Wheeler BW, Mills J, Ben-Shlomo Y. Health promotion and the social gradient: the free swimming initiative for children and young people in Bristol. Public Health. 2012;126(11):976-981. PubMed ID: 22902210 doi:10.1016/j.puhe.2012.07.008

16. Koorts H, Gillison F. Mixed method evaluation of a communitybased physical activity program using the RE-AIM framework: practical application in a real-world setting. BMC Public Health. 2015;15(1):1102. doi:10.1186/s12889-015-2466-y

17. De Meij JSB, Chinapaw MJM, Kremers SPJ, Van der wal MF, Jurg ME, Van Mechelen W. Promoting physical activity in children: the stepwise development of the primary school-based JUMP-in intervention applying the RE-AIM evaluation framework. Br J Sports Med. 2010;44(12):879-887. PubMed ID: 19019902 doi:10.1136/ bjsm.2008.053827

18. Taylor L, Clark A, Wilk P, Button B, Gilliland J. Exploring the effect of perceptions on children's physical activity in varying geographic contexts: using a structural equation modelling approach to examine a cross-sectional dataset. Children. 2018;5(12):159. doi:10.3390/ children5120159

19. Pate RR, Trost SG, Mullis R, Sallis JF, Wechsler H, Brown DR. Community interventions to promote proper nutrition and physical activity among youth. Prev Med. 2000;31(2):S138-S149. PubMed ID: 19019902 doi:10.1006/pmed.2000.0632

20. Nickelson J, Alfonso ML, McDermott RJ, Bumpus EC, Bryant CA, Baldwin JA. Characteristics of "tween" participants and nonparticipants in the VERB ${ }^{\mathrm{TM}}$ summer scorecard physical activity promotion program. Health Educ Res. 2011;26(2):225-238. PubMed ID: 21303817 doi:10.1093/her/cyq089
21. Taylor LG, Clark AF, Gilliland JA. Context matters: examining children's perceived barriers to physical activity across varying Canadian environments. Health Place. 2018;54:221-228. PubMed ID: 30368100 doi:10.1016/j.healthplace.2018.10.002

22. Estabrooks PA, Lee RE, Gyurcsik NC. Resources for physical activity participation: does availability and accessibility differ by neighborhood socioeconomic status? Ann Behav Med. 2003;25(2):100-104. PubMed ID: 12704011 doi:10.1207/S15324796ABM2502_05

23. Casey R, Oppert JM, Weber C, et al. Determinants of childhood obesity: what can we learn from built environment studies? Food Qual Prefer. 2014;31(1):164-172. doi:10.1016/j.foodqual.2011. 06.003

24. Beaulac J, Olavarria M, Kristjansson E. A community-based hip-hop dance program for youth in a disadvantaged community in Ottawa: implementation findings. Health Promot Pract. 2010;11(3 suppl): 61S-69S. PubMed ID: 20488970 doi:10.1177/1524839909353738

25. Mitchell CA, Clark AF, Gilliland JA. Built environment influences of children's physical activity: examining differences by neighbourhood size and sex. Int J Environ Res Public Health. 2016;13(1):130. doi:10. 3390/ijerph13010130

26. Butler EN, Ambs AMH, Reedy J, Bowles HR. Identifying GIS measures of the physical activity built environment through a review of the literature. J Phys Act Health. 2011;8(s1):S91-S97. doi:10. 1123/jpah.8.s1.s91

27. Schneider M, DeBar L, Calingo A, et al. The effect of a communications campaign on middle school students' nutrition and physical activity: results of the HEALTHY study. J Health Commun. 2013; 18(6):649-667. PubMed ID: 23409792 doi:10.1080/10810730.2012. 743627

28. Saunders RP, Pate RR, Dowda M, Ward DS, Epping JN, Dishman RK. Assessing sustainability of lifestyle education for activity program (LEAP). Health Educ Res. 2012;27(2):319-330. PubMed ID: 22156233 doi:10.1093/her/cyr111

29. Tucker P, Irwin JD, Gilliland J, He M, Larsen K, Hess P. Environmental influences on physical activity levels in youth. Health Place. 2009;15(1):357-363. PubMed ID: 18706850 doi:10.1016/j. healthplace.2008.07.001

30. Reimers AK, Wagner M, Alvanides S, et al. Proximity to sports facilities and sports participation for adolescents in Germany. PLoS ONE. 2014;9(3):e93059. doi:10.1371/journal.pone.0093059

31. Page AS, Cooper AR, Griew P, Jago R. Independent mobility, perceptions of the built environment and children's participation in play, active travel and structured exercise and sport: the PEACH Project. Int J Behav Nutr Phys Act. 2010;7(1):17. doi:10.1186/14795868-7-17

32. Shaw B, Watson B, Frauendienst B, Redecker A, Jones T. Children's Independent Mobility: A Comparative Study in England and Germany (1971-2010). London, UK: Policy Studies Institute; 2013.

33. Badland H, Oliver M, Duncan M, Schantz P. Measuring children's independent mobility: comparing objective and self-report approaches. Child Geogr. 2011;9(2):263-271. doi:10.1080/14733285.2011. 562386

34. Loebach JE, Gilliland JA. Free range kids? Using GPS-derived activity spaces to examine children's neighborhood activity and mobility. Environ Behav. 2016;48(3):421-453. doi:10.1177/0013916514543177

35. Wilk P, Clark AF, Maltby A, Tucker P, Gilliland JA. Exploring the effect of parental influence on children's physical activity: the mediating role of children's perceptions of parental support. Prev Med. 2018;106:79-85. doi:10.1016/j.ypmed.2017.10.018

36. Tappe KA, Glanz K, Sallis JF, Zhou C, Saelens BE. Children's physical activity and parents' perception of the neighborhood environment: neighborhood impact on kids study. Int J Behav Nutr Phys 
Act. 2013;10:39. PubMed ID: 23531282 doi:10.1186/1479-586810-39

37. Kurka JM, Adams MA, Todd M, et al. Patterns of neighborhood environment attributes in relation to children's physical activity. Health Place. 2015;34:164-170. PubMed ID: 26057609 doi:10. 1016/j.healthplace.2015.05.006

38. Verstraete SJM, Cardon GM, De Clercq DLR, De Bourdeaudhuij IMM. Increasing children's physical activity levels during recess periods in elementary schools: the effects of providing game equipment. Eur J Public Health. 2006;16(4):415-419. PubMed ID: 16431866 doi:10.1093/eurpub/ck1008

39. Kunin-Batson AS, Seburg EM, Crain AL, et al. Household factors, family behavior patterns, and adherence to dietary and physical activity guidelines among children at risk for obesity. J Nutr Educ Behav. 2015;47(3):206-215.e1. doi:10.1016/j.jneb. 2015.01.002

40. Gilliland JA, Clark AF, Tucker P, Prapavessis H, Avison W, Wilk P. The ACT-i-Pass study protocol: how does free access to recreation opportunities impact children's physical activity levels? BMC Public Health. 2015;15(1):1286. doi:10.1186/s12889-0152637-x

41. ArcMap Desktop [computer program]. Version 10.4. Redlands, CA: Environmental Systems Research Institute; 2017.

42. Robbins LB, Stommel M, Hamel LM. Social support for physical activity of middle school students. Public Health Nurs. 2008; 25(5):451-460. PubMed ID: 18816362 doi:10.1111/j.1525-1446. 2008.00729.x

43. Welk GJ, Wood K, Morss G. Parental influences on physical activity in children: an exploration of potential mechanisms. Pediatr Exerc Sci. 2003;15:19-33.
44. Trost SG, Pate RR, Sallis JF, et al. Age and gender differences in objectively measured physical activity in youth. Med Sci Sports Exerc. 2002;34(2):350-355. PubMed ID: 11828247

45. Statistics Canada. 2016 Census Dictionary. Catalogue no. 98-301XWE. Ottawa, ON: Statistics Canada. https://www12.statcan.gc.ca/ census-recensement/2011/ref/dict/geo021-eng.cfm. Published 2016. Accessed January 2, 2019.

46. IBM SPSS Statistics for Windows [computer program]. Version 24. Armonk, NY: IBM Corp; 2016.

47. Stata Statistical Software [computer program]. Version 15. College Station, TX: StataCorp LLC; 2017.

48. Weinberg R, Tenenbaum G, McKenzie A, et al. Motivation for youth participation in sport and physical activity: relationships to culture, self-reported activity levels, and gender. Int J Sport Psychol. 2000; 31:321-364.

49. Boys \& Girls Club of London. Mission and Core Values. http://www. bgclondon.ca/about-us/mission-and-core-values. Published 2018. Accessed January 2, 2019.

50. Telford RM, Telford RD, Olive LS, Cochrane T, Davey R. Why are girls less physically active than boys? Findings from the LOOK longitudinal study. PLoS ONE. 2016;11(3):e0150041. doi:10.1371/ journal.pone.0150041

51. Cureton K, Frisby W. Staff perspectives on how social liberal and neo-liberal values influence the implementation of leisure access policy. Int J Sport Policy Politics. 2011;3(1):3-22. doi:10.1080/ 19406940.2010.544665

52. Healy MA, Gilliland JA. Quantifying the magnitude of environmental exposure misclassification when using imprecise address proxies in public health research. Spat Spatiotemporal Epidemiol. 2012;3(1): 55-67. PubMed ID: 22469491 doi:10.1016/j.sste.2012.02.006 